\title{
Induction of Resistance to Schistosoma mansoni Infection in Mice by Purified Parasite Paramyosin
}

Timothy P. Flanigan, Charles H. King, Ronald R. Lett, Jayasri Nanduri, and Adel A. F. Mahmoud

Division of Geographic Medicine, Department of Medicine, Case Western Reserve University and

University Hospitals of Cleveland, Cleveland, Ohio 44106

\begin{abstract}
Freeze-thaw (FT)-disrupted schistosomula or their membrane extract induced significant resistance in mice to Schistosoma mansoni infection (34 and $25 \%$, respectively) without the use of adjuvant. Antigens identified in schistosome extracts by sera from immunized animals were then evaluated for protective potential. Immunization with schistosomal antigens of 97 and 68-70 kD resulted in significant protection that was equivalent to that obtained by FT schistosomula. Since the 97-kD antigen was suggested to be parasite paramyosin, we used a biochemical technique to purify this muscle protein. Purified schistosome paramyosin ran as a single band on $10 \%$ SDS-PAGE and was recognized both by sera from mice immunized with FT schistosomula and a polyclonal antiserum raised against the 97-kD parasite protein. Preincubation of schistosome paramyosin with sera from mice immunized with FT schistosomula resulted in the removal of reactivity with the $97-\mathrm{kD}$ protein in crude worm extracts. Paramyosin was identified by Western blotting to be in the tegument of schistosomula. The purified schistosome paramyosin resulted in significant protection in three separate experiments $(24,46$, and $53 \%)$ without the use of adjuvant. Addition of BCG to paramyosin resulted in enhanced protection.
\end{abstract}

\section{Introduction}

Induction of resistance against human schistosome infection represents a major goal for control programs. The multicellular and complex nature of these organisms results in divergent immunologic responses in the mammalian host that can be either harmful or beneficial (1). For example, purified glycoprotein antigens of the ova induce granuloma formation around parasite eggs deposited in host tissues (2). In contrast, immunomodulatory responses such as induction of $T$ suppressor cells that may limit the extent of disease are the result of host reactivity to different components of the parasite (3). Similarly, resistance to schistosomiasis has been shown to be based on several mechanisms including innate and acquired with both specific and nonspecific components (4). Although the effector constituents of the host responses contributing to

Dr. Lett's current address is Department of Surgery, University of Alberta, Edmonton, Alberta, Canada.

Address all correspondence to Dr. Timothy P. Flanigan, Department of Medicine, University Hospitals, Cleveland, OH 44106.

Received for publication 27 July 1987 and in revised form $19 \mathrm{Au}$ gust 1988.

J. Clin. Invest.

(C) The American Society for Clinical Investigation, Inc.

$0021-9738 / 89 / 03 / 1010 / 05 \$ 2.00$

Volume 83, March 1989, 1010-1014 protection have been examined thoroughly (5), characterization of the protective parasite antigens is only beginning.

Earlier attempts to define protective schistosome antigens from crude parasite preparations produced conflicting results $(6,7)$. In the present study we have demonstrated that freezethaw (FT) ${ }^{1}$-disrupted schistosomula or their membrane extract induced significant resistance in mice without the use of adjuvants. Two candidate parasite antigens of 97 and $68-70 \mathrm{kD}$ were shown to give equivalent degrees of protection. The purified $97-\mathrm{kD}$ antigen appeared to be schistosome paramyosin; upon injection into mice it induced significant protection without adjuvant.

\section{Methods}

Parasites. A Puerto Rican strain of Schistosoma mansoni, maintained in our laboratory, was used in these studies. Schistosomula were obtained by cercarial penetration of isolated mouse skin (8). The organisms were washed extensively in PBS and counted. They were then centrifuged at $400 \mathrm{~g}$ at $4^{\circ} \mathrm{C}$ for $2 \mathrm{~min}$ and subjected to four cycles of FT before use in protection studies. Mechanically transformed schistosomula were prepared as previously described (9). The organisms were then incubated at $37^{\circ} \mathrm{C}$ in an atmosphere of $5 \% \mathrm{CO}_{2}$ for $3 \mathrm{~h}$ in serumfree media. To prepare membrane extract of schistosomula, 50,000 mechanically transformed organisms were added to $0.25 \mathrm{ml}$ of $1 \%$ Triton X-100 (Polysciences Inc., Warrington, PA) with 1 mM PMSF (Sigma Chemical Co., St. Louis, MO) and $5 \mathrm{mM}$ iodoacetamide (Sigma Chemical Co.). The organisms were kept at $4^{\circ} \mathrm{C}$ and vortexed every $5 \mathrm{~min}$ for $30 \mathrm{~min}$ and then centrifuged at $3,000 \mathrm{~g}$. Clear supernatant was removed and immediately used for vaccination and immunochemical studies.

Soluble worm antigen preparation (SWAP) was obtained as previously described (10). SWAP was prepared in the presence of protease inhibitors by incubating adult worms at $4^{\circ} \mathrm{C}$ for $30 \mathrm{~min}$ in $1 \mathrm{mM}$ diisopropyl fluorophosphate (Sigma Chemical Co.). The organisms were then homogenized with $5 \mathrm{mM}$ PMSF, $5 \mathrm{mM} N$ - $\alpha$-D-tosyl-L-lysine chloromethylketone (Sigma Chemical Co.), and $5 \mathrm{mM}$ iodoacetamide.

Induction and assay of resistance. CF1 female mice (Charles River Breeding Laboratories, Wilmington, MA) weighing 18-20 $\mathrm{g}$ were used in groups of 6-10 animals. For protection experiments using FT schistosomula, each animal was injected subcutaneously with $\sim 2,000$ organisms twice at 2-wk intervals and challenged with cercariae after another $2 \mathrm{wk}$. Control mice received similar injections of PBS. BCG was used at a dose of $5 \times 10^{6} \mathrm{CFU} /$ dose (University of Illinois, Chicago, IL). Induction of protection by subcutaneous injection of schistosomula extract or individual antigen preparations followed the same time schedule. Resistance in vaccinated and control animals was assayed by exposure of mice to freshly shed cercariae. Groups of animals were anesthetized and their abdomens shaved, and then they were individually exposed to 100 or 500 cercariae. Lung recovery of schistosomula was performed at day 5 and adult worm perfusion was performed at 6-8 wk (11). Protection was calculated as

1. Abbreviations used in this paper: FT, freeze-thaw; SWAP, soluble worm antigen preparation. 
$1-\frac{\text { mean number of worms in immunized mice }}{\text { mean number of worms in control mice }} \times 100$.

Differences between the means were analyzed by the 2-tailed $t$ test. Characterization of protective antigens. Sera from immunized mice were used as probes in Western blotting studies to determine the antigenic components of crude schistosome preparations. Aliquots of 50-100 $\mu \mathrm{g}$ of SWAP or schistosomula extract were mixed with equal volumes of sample buffer containing 2-mercaptoethanol. Polypeptides were separated on $10 \%$ SDS-PAGE and transferred electrophoretically to nitrocellulose paper $(12,13)$. Strips of nitrocellulose with the transferred proteins were reacted with 1:10-1:25 dilution of sera from normal or vaccinated mice. Bound antibodies were detected with horseradish peroxidase goat anti-mouse IgG (Bio-Rad Laboratories, Richmond, CA) as conjugate and 4-chloronaphthol as substrate.

To determine if antigens recognized by immune sera were protective, parasite proteins were separated on SDS-PAGE gels and slices of gel were cut to correspond to the molecular weights of desired antigens. The gel slices were homogenized in PBS and injected subcutaneously. Control animals received gel slices without electrophoresed proteins. Immunization schedule was similar to that outlined above.

Purification and testing of schistosome paramyosin. Two proteins of 97 and $68-70 \mathrm{kD}$ were found to be protective. The $97-\mathrm{kD}$ protein was selected for further evaluation, as the work of Lanar et al. indicated it may be schistosome paramyosin (14). A polyclonal rabbit serum was raised by repeated subcutaneous injections at 2-wk intervals of $10 \%$ SDS-PAGE slices containing the $97-\mathrm{kD}$ protein. Furthermore, we extracted parasite paramyosin from adult schistosomes according to the procedure of Harris and Epstein (15). Briefly, adult worms were homogenized in PBS in the presence of protease inhibitors $(1 \mathrm{mM}$ ethylenediaminetetracetic acid, $1 \mathrm{mM}$ PMSF, and $5 \mathrm{mM}$ DTT) (Sigma Chemical Co.). Actomyosin was solubilized in $0.6 \mathrm{M} \mathrm{KCl}$ and paramyosin was then separated from actomyosin by ultracentrifugation at $100,000 \mathrm{~g}$ for $3 \mathrm{~h}$ at $4^{\circ} \mathrm{C}$. Solubilization in $0.6 \mathrm{M} \mathrm{KCl}$ and then reprecipitation in $0.1 \mathrm{M} \mathrm{KCl}$ removed several minor contaminants (16). The extent of purification of the isolated paramyosin was confirmed on a $10 \%$ SDS-PAGE and by Western blot with the anti-97-kD rabbit serum and sera from mice immunized with FT schistosomula. Furthermore, to assess the immunologic identity of the purified schistosome paramyosin, $100 \mu \mathrm{l}$ of sera from mice immunized with FT schistosomula was incubated overnight at $4^{\circ} \mathrm{C}$ with $100 \mu \mathrm{g}$ of paramyosin and then analyzed by Western blot. The protective effect of the parasite protein was then evaluated by injection of $5 \mu \mathrm{g}$ of paramyosin in groups of mice at 2-wk intervals. Mice were challenged and adult worm burden assessed at $6 \mathrm{wk}$ as previously described. Serum from mice injected with paramyosin or PBS was assessed for specific antibody by Western blot analysis.

\section{Results}

Induction of resistance by crude schistosome preparations. Groups of mice (6-10 each) were immunized twice at 2-wk intervals with $\sim 2,000$ FT schistosomula per injection. Control animals received injections of PBS according to the same schedule. In six separate experiments significant protection was observed upon recovery of lung schistosomula on day 5 after challenge (Table I). In individual experiments the mean protection in immunized mice varied from $21-47 \%$. The optimal parasite dose was then evaluated. Groups of mice were immunized twice with $\sim 1,000,2,000$, or 5,000 schistosomula. Significantly higher protection $(30 \%)$ was demonstrated in animals immunized with 2,000 organisms $(P<0.01)$. Subsequently, we used detergent extract of schistosomula to determine if it was equally protective. An extract of 5,000 schistosomula given twice at 2-wk intervals to CF1 mice resulted in $27 \%$ protection $(P<0.02)$ as compared with immunization
Table I. Induction of Resistance by FT Schistosomula

\begin{tabular}{ccccc}
\hline & \multicolumn{5}{c}{$\begin{array}{c}\text { Mean no. of schistosomula } \\
\text { recovered }( \pm \text { SD })\end{array}$} & \% Protection \\
\cline { 3 - 4 } Experiment & $\begin{array}{c}\text { No. of mice } \\
\text { in each group }\end{array}$ & Control & FT schistosomula & $(P$ value $)$ \\
\hline 1 & 5 & $146 \pm 18$ & $114 \pm 6$ & $22 \%(P<0.001)$ \\
2 & 5 & $190 \pm 19$ & $100 \pm 10$ & $47 \%(P<0.001)$ \\
3 & 5 & $112 \pm 4$ & $88 \pm 7$ & $27 \%(P<0.001)$ \\
4 & 5 & $105 \pm 12$ & $77 \pm 5$ & $29 \%(P<0.001)$ \\
5 & 5 & $189 \pm 12$ & $121 \pm 4$ & $36 \%(P<0.001)$ \\
6 & 9 & $145 \pm 13$ & $86 \pm 5$ & $41 \%(P<0.001)$ \\
Mean of six & & & & \\
experiments & & $148 \pm 36$ & $98 \pm 17$ & $34 \%(P<0.020)$
\end{tabular}

Each animal was injected subcutaneously with $\sim$ FT 2,000 organisms at days 1 and 14 and then exposed to 500 cercariae percutaneously on day 28 . Recovery of lung schistosomula was performed on day 5 after challenge.

with $1 \%$ Triton $\mathrm{X}-100$ alone as control (Table II). These results were confirmed by performing adult worm perfusion at $6 \mathrm{wk}$; a mean of $22 \%$ protection $(P<0.05)$ was again observed.

Sera from vaccinated and control mice were analyzed by Western blot against schistosomula extract and SWAP prepared with protease inhibitors. Sera from mice immunized with FT schistosomula consistently recognized in SWAP a single band at $97 \mathrm{kD}$ (Fig. $1 \mathrm{~A}$ ), or a doublet at 97 and $92 \mathrm{kD}$ (Fig. $1 E$ ). A similar pattern was seen when the sera were reacted with schistosomula extract. Sera from mice immunized with schistosomula detergent extract recognized bands at 200,97 , and $68-70 \mathrm{kD}$ in SWAP (data not shown).

Due to the simple humoral response and the availability of SWAP, the protective effect of the $97-$ and $68-70-\mathrm{kD}$ proteins recognized in SWAP by immune sera were examined further. After electrophoresis of SWAP, gel slices corresponding to 92-97 and 65-70 kD mol wt were excised and used to immunize groups of CF1 mice. The $97-$ and the $68-70-\mathrm{kD}$ antigens resulted in a respective mean reduction of schistosomula recovery of $40 \%(P<0.001)$ and $48 \%(P<0.001)$ (Table II).

Characterization of protective potential of schistosome paramyosin. Extraction and purification of paramyosin from adult $S$. mansoni resulted in isolation of a single band at $97 \mathrm{kD}$ on Coomassie Blue staining on $10 \%$ SDS-PAGE (Fig. $1 \mathrm{~B}$ ). Western blot analysis showed that this preparation was recognized both by sera from mice immunized with FT schistosomula and by a polyclonal rabbit sera raised against the $97-\mathrm{kD}$ antigen (Fig. $1 C$ ). Furthermore, schistosome paramyosin absorbed the immunological recognition of the $97-\mathrm{kD}$ antigen by sera from mice immunized with FT schistosomula (Fig. $1 E$ ). Injection of $5 \mu \mathrm{g}$ of this purified material twice in groups of CF 1 mice in three separate experiments resulted in a mean protection of 24,46 , and $53 \%(P<0.02)$ as assessed by adult worm perfusion at $7 \mathrm{wk}$ (Table III).

To determine whether paramyosin-induced protection can be enhanced with BCG, studies summarized in Table III were performed. Paramyosin alone resulted in $24 \%$ protection and the addition of BCG enhanced this protection to $52 \%(P$ $<0.01)$. BCG alone resulted in $24 \%$ protection $(P<0.05)$. Furthermore, sera from immunized mice recognized two 
Table II. Induction of Resistance by Schistosomula Membrane Extract and Purified Schistosome Proteins

\begin{tabular}{|c|c|c|c|c|c|}
\hline \multirow[b]{2}{*}{ Experiment } & \multirow[b]{2}{*}{ Parasite preparation } & \multirow{2}{*}{$\begin{array}{l}\text { No. of mice } \\
\text { in each group }\end{array}$} & \multicolumn{2}{|c|}{$\begin{array}{l}\text { Mean no. of schistosomula } \\
\text { recovered }( \pm \mathrm{SD})\end{array}$} & \multirow{2}{*}{$\begin{array}{l}\text { \% Protection } \\
(P \text { value })\end{array}$} \\
\hline & & & Control & Immunized & \\
\hline 1 & $1 \%$ Triton X-100 extract of 5,000 schistosomula & 5 & $159 \pm 9$ & $115 \pm 11$ & $27 \%(P<0.02)$ \\
\hline 2 & Gel slice with $97-\mathrm{kD}$ protein & 4 & $166 \pm 13$ & $117 \pm 12$ & $30 \%(P<0.001)$ \\
\hline 3 & Gel slice with $97-k D$ protein & 6 & $174 \pm 8$ & $91 \pm 11$ & $48 \%(P<0.001)$ \\
\hline 4 & Gel slice with $97-\mathrm{kD}$ protein & 9 & $145 \pm 13$ & $86 \pm 5$ & $41 \%(P<0.001)$ \\
\hline 5 & Gel slice with $68-70-\mathrm{kD}$ protein & 6 & $174 \pm 8$ & $91 \pm 8$ & $48 \%(P<0.001)$ \\
\hline
\end{tabular}

Each animal was injected subcutaneously with various doses of antigen on days 1 and 14 and then exposed to 500 cercariae percutaneously on day 28. Recovery of lung schistosomula was performed on day 5 after challenge. Control animals in experiment 1 received PBS and control animals in experiments 2-5 received polyacrylamide gel slice alone. Animals in experiment 2 received only one dose of antigen and were then challenged on day 14.

bands at 92-97 kD in SWAP and reacted strongly with parasite paramyosin (Fig. $1 \mathrm{D}$ ).

Localization of paramyosin. To assess if paramyosin is present in the membrane component of schistosomula, we examined the reactivity of sera from mice immunized with a mild nonionic detergent membrane extract of schistosomula against purified paramyosin. Sera from immunized mice reacted with purified paramyosin by Western blot analysis, whereas control mouse sera raised against $1 \%$ Triton X-100 alone did not react to paramyosin (data not shown).

\section{Discussion}

The multiplicity of antigens and of host responses to helminthic parasites poses several problems in identifying those of potential protective relevance. Although resistance to $S$. mansoni in mice can be induced by irradiated cercariae (17), the protective parasite components are unknown. On the other hand, the development of monoclonal antischistosome antibodies that adoptively confer resistance has led to characterization of several potential protective antigens. Smith and Clegg have reported the isolation of two protective antigens of 155 and $53 \mathrm{kD}$ that in conjunction with adjuvant have induced significant protection of $21 \%$ (18). King et al. have isolated an antigen of $68 \mathrm{kD}$ from SWAP that induced protection of $30-66 \%$ without adjuvant (19). Furthermore, Balloul et al. have described immunization with a recombinant fusion protein containing a portion of a $28-\mathrm{kD}$ schistosome antigen that provides 52 and $67 \%$ protection in hamsters and mice, respectively (20).

In the current study we made use of another model of inducing resistance to $S$. mansoni in mice without adjuvant that we originally described (21). FT preparations of schistosomula and a Triton X-100 extract of the parasite without

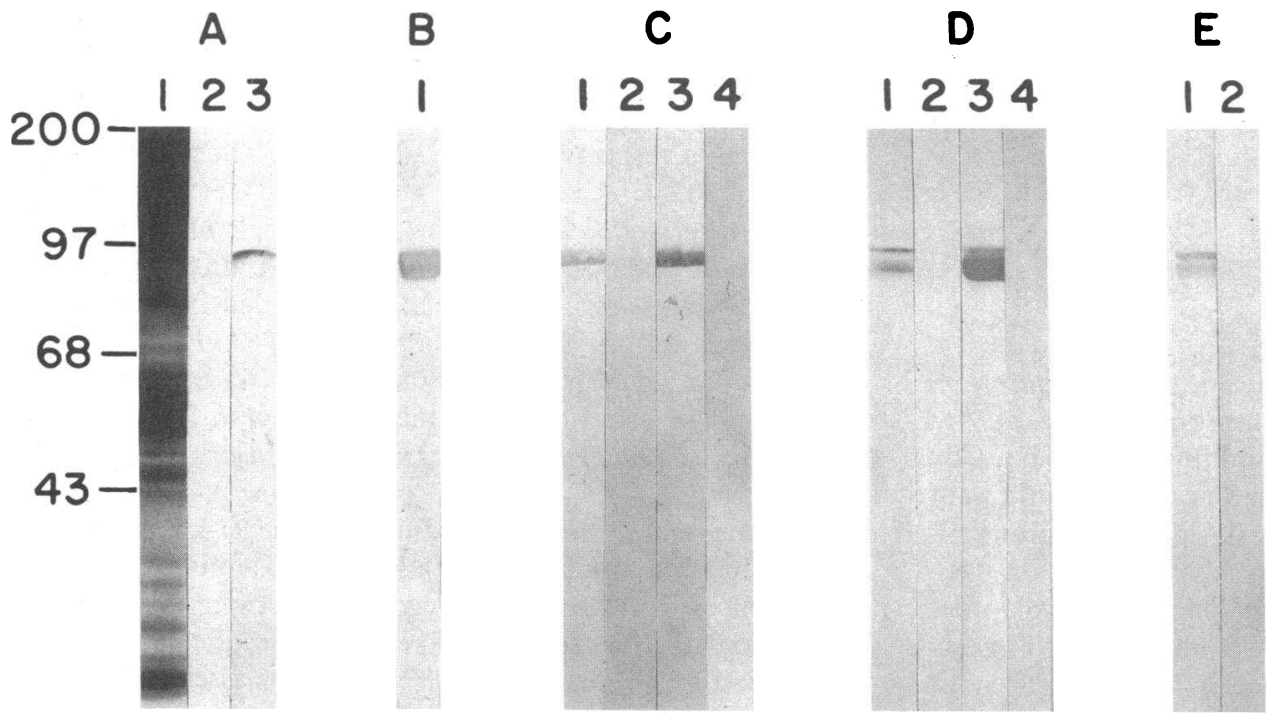

Figure 1. Immunologic reactivity of sera from mice immunized with various schistosome proteins. $(A)$ Sera were reacted with SWAP separated on $10 \%$ SDS-PAGE in the presence of 2-mercaptoethanol. Lane 1 , sera from mice chronically infected with $S$. mansoni. Lane 2, sera from mice immunized with PBS. Lane 3, sera from mice immunized with FT schistosomula recognized a single band at $97 \mathrm{kD}$. $(B)$ Coomassie blue staining of a $10 \%$ SDS-PAGE of purified schistosome paramyosin shows a broad band at $97 \mathrm{kD}$. (C) Reactivity of various sera against schistosome paramyosin. Lane 1, sera from mice immunized with FT schistosomula reacted with paramyosin. Lane 2 , sera from mice immunized with PBS. Lane 3, a polyclonal rabbit

serum raised against the $97-\mathrm{kD}$ schistosome protein reacts with paramyosin. Lane 4, preimmune rabbit sera. $(D)$ Lane 1 , sera from mice immunized with paramyosin recognized a doublet at 92 and $97 \mathrm{kD}$ when reacted with SWAP. Lane 3, sera from mice immunized with paramyosin reacted with schistosome paramyosin. Lanes 2 and 4, sera from mice immunized with PBS showed no reactivity with SWAP and paramyosin, respectively. $(E)$ Preincubation of sera from mice immunized with FT schistosomula with schistosome paramyosin absorbed the immunologic reactivity to the 97 - and $92-\mathrm{kD}$ protein. Lane 1 , sera from mice immunized with FT schistosomula reacted against SWAP. Lane 2 , reactivity of the above sera with SWAP after it has been preincubated with schistosome paramyosin. 
Table III. Induction of Resistance by Paramyosin Purified from Adult S. mansoni

\begin{tabular}{|c|c|c|c|c|}
\hline Experiment & Preparation & $\begin{array}{c}\text { No. of } \\
\text { mice in } \\
\text { each group }\end{array}$ & $\begin{array}{l}\text { Mean no. of } \\
\text { adult worms } \\
\text { recovered } \\
( \pm \mathrm{SD})\end{array}$ & $\begin{array}{c}\% \text { Protection } \\
(P \text { value })\end{array}$ \\
\hline \multirow[t]{2}{*}{1} & PBS & 8 & $19 \pm 7$ & \\
\hline & Paramyosin & 7 & $9 \pm 6$ & $53 \%(P<0.01)$ \\
\hline \multirow[t]{2}{*}{2} & PBS & 8 & $24 \pm 10$ & \\
\hline & Paramyosin & 8 & $13 \pm 10$ & $46 \%(P<0.05)$ \\
\hline \multirow[t]{5}{*}{3} & PBS & 8 & $38 \pm 8$ & \\
\hline & Paramyosin & 8 & $29 \pm 8$ & $24 \%(P<0.05)$ \\
\hline & BCG & 7 & $29 \pm 5$ & \\
\hline & ${ }^{* \neq}$ Paramyosin & & & \\
\hline & $+\mathrm{BCG}$ & 7 & $18 \pm 7$ & $52 \%(P<0.01)$ \\
\hline
\end{tabular}

Each animal was injected subcutaneously with $5 \mu \mathrm{g}$ of paramyosin in $100 \mu \mathrm{l}$ of PBS on days 1 and 14 and then exposed to 100 cercariae on day 28. Mice were perfused after 6 wk to assess adult worm burden. Control mice (eight in each group) received $100 \mu$ l of PBS alone. * Immunization with paramyosin + BCG when compared with BCG alone was significantly protective $(38 \%, P<0.02)$.

‡ Immunization with paramyosin + BCG when compared with immunization with paramyosin alone was significantly protective $(38 \%$, $P<0.05)$.

adjuvant produced a significant degree of protection $(21-47 \%)$. James et al. have shown that immunization of mice with FT schistosomula in conjunction with BCG results in significant protection (22). Although immunization with FT schistosomula and Triton X-100 extract of schistosomula provide a multitude of parasite antigens, a strong monospecific humoral response was observed in vaccinated mice. For example, sera from mice immunized with Triton X-100 extract of schistosomula recognized antigens of $\sim 200,97$, and $68-70$ $\mathrm{kD}$ mol wt, whereas sera from mice immunized with FT schistosomula recognized only a $97-\mathrm{kD}$ antigen or a doublet at 97 and $92 \mathrm{kD}$ in SWAP. Immunization of mice with gel slices containing the 97- or the $68-70-\mathrm{kD}$ antigens indicated that both were significantly protective. The unique features of our immunization protocol are that no adjuvant is used and that only minute quantities of antigen are needed ( $\sim 5 \mu \mathrm{g} / \mathrm{injec}-$ tion per mouse).

Sher et al., using sera from mice immunized with FT schistosomula and BCG, detected antigens at 180, 95, and 78 $\mathrm{kD}$ in SWAP run on a nonreducing gel (23). When SWAP was prepared in the presence of protease inhibitors and run on a reducing gel, the same sera recognized only a single band at 97 kD (23). Recently it was reported that a DNA that encoded about half of the $97-\mathrm{kD}$ protein has been cloned and sequenced (14). The deduced amino acid sequence shares homology with invertebrate paramyosin. Furthermore, a MAb to the $97-\mathrm{kD}$ protein recognized purified schistosome paramyo$\sin (14,24)$. To characterize further the biochemical nature of the protective schistosome antigens, we isolated parasite paramyosin. Using the biochemical procedure of Harris and Epstein (15), the purified preparation was demonstrated as a single band on SDS-PAGE and recognized on Western blot both by sera from mice immunized with FT schistosomula and by a rabbit serum raised against the $97-\mathrm{kD}$ native protein isolated from schistosomes. Sera from paramyosin immunized mice recognized two bands at 97 and $92 \mathrm{kD}$ when reacted by Western blot against SWAP. Furthermore, purified schistosome paramyosin absorbed completely the reactivity of sera from mice immunized with FT schistosomula with the 97- and $92-\mathrm{kD}$ parasite antigens. The $92-\mathrm{kD}$ protein is probably a breakdown product of paramyosin, as antibody to the $92-\mathrm{kD}$ protein is absorbed by schistosome paramyosin. The protective potential of purified schistosome paramyosin was subsequently evaluated. Two injections of $5 \mu \mathrm{g} /$ mouse of the purified schistosome protein at 2-wk intervals resulted in 24, 46, and $53 \%$ protection as assessed by adult worm recovery. Addition of BCG to paramyosin resulted in a mean protection of $52 \%$. When compared with immunization with BCG alone, protection was significantly enhanced $(P<0.02)$.

Paramyosin has previously been well characterized in invertebrates as an integral muscle protein that allows for extremely prolonged and powerful muscle contraction (25). We demonstrated that antibody to a mild nonionic detergent membrane extract of schistosomula reacted to purified paramyosin on Western blot analysis. The presence of the protein in the tegument of schistosomula may explain its immunogenicity in the FT schistosomula model. Pearce et al. found binding of a MAb against paramyosin just beneath and possibly within the surface of adult schistosomes, though it was suggested that paramyosin is not surface exposed (24). Ultrastructural studies using electron microscopy and a polyclonal antibody against paramyosin demonstrated paramyosin firmly embedded within the tegument (26).

Our data indicate that immunologically defined components of schistosome extracts are capable of inducing signifcant protection without the use of adjuvant. Two schistosome antigens of 97 and $68-70 \mathrm{kD}$ resulted in equivalent protection to that obtained by FT schistosomula. We purified a $97-\mathrm{kD}$ antigen from worm extracts that corresponded to parasite paramyosin. It was recognized by sera from mice immunized with FT schistosomula and by a polyclonal antiserum raised against the $97-\mathrm{kD}$ native parasite protein. Preincubation of schistosome paramyosin with sera from mice immunized with FT schistosomula resulted in the removal of reactivity with the 97-kD protein. Finally, the purified schistosome paramyosin resulted in significant protection (without the use of adjuvant) comparable to that obtained by any previously described protective schistosome antigens.

\section{Acknowledgments}

We would like to acknowledge Dr. Simon Caroll for helpful suggestions, Vanessa Scott and Pierre Peters for expert technical assistance, and the secretarial help of Karen Mong.

This work was supported in part by grants from The Edna McConnell Clark Foundation and The John D. and Catherine T. MacArthur Foundation.

Note added in proof. Since the submission of this manuscript, Pearce et al. (27) have reported that paramyosin administered with BCG at a total dose of 4-40 $\mu \mathrm{g} /$ mouse conferred significant protection against $S$. mansoni challenge infection.

\section{References}

1. Mahmoud, A. A. F. 1984. Schistosomiasis. In Tropical and Geographic Medicine. K. S. Warren and A. A. F. Mahmoud, editors. McGraw Hill Book Co., New York. 443-457. 
2. Lustigman, S., A. A. F. Mahmoud, and J. Hamburger. 1985. Glycopeptides in soluble egg antigen of Schistosoma mansoni: isolation, characterization, and elucidation of their immunochemical and immunopathological relation to the major egg glycoprotein (MEG). $J$. Immunol. 134:1961-1967.

3. Rocklin, R. E., A. P. Brown, K. S. Warren, R. P. Pelley, V. Houba, T. K. A. Siongok, H. Ouma, R. F. Sturrock, and A. E. Butterworth. 1980. Factors that modify the cellular-immune response in patients infected by Schistosoma mansoni. J. Immunol. 125:19161923.

4. Smithers, S. R., and M. J. Doenhoff. 1982. Schistosomiasis. In Immunology of Parasitic Infections. S. Cohen and K. S. Warren, editors. Blackwell Scientific Publications, Oxford. 527-607.

5. Butterworth, A. E., D. W. Taylor, M. F. Veith, M. A. Vadas, A. Dessein, R. F. Sturrock, and E. Wells. 1982. Studies on the mechanisms of immunity in human schistosomiasis. Immunol. Rev. 61:5-39.

6. Murrell, K. D., Dean, D. A., and E. E. Stafford. 1975. Resistance to infection with Schistosoma mansoni after immunization with worm extracts or live cercariae: role of cytotoxic antibody in mice and guinea pigs. Am. J. Trop. Med. Hyg. 24:955-962.

7. Murrell, K. D., Minard, P., Carney, W. P., Dean, D. A., Vannier, W. E., and W. G. Clutter. 1978. Experimental vaccines in schistosomiasis. Proc. Int. Conf. Schistosomiasis. 2:545.

8. Clegg, J. A., and S. R. Smithers. 1972. The effects of immune Rhesus monkey serum on schistosomula of Schistosoma mansoni during cultivation in vitro. Int. J. Parasitol. 2:79-98.

9. Ramalho-Pinto, F. J., R. E. Gazzinelli, T. A. Howells, E. A. Mota-Santos, E. A. Figueiredo, and J. Pelligrino. 1974. Schistosoma mansoni: defined system for a step-wise transformation of cercariae to schistosomula in vitro. Exp. Parasitol. 36:360-372.

10. Colley, D. G., J. A. Cook, G. L. Freeman, R. K. Bartholomew, and P. Jordan. 1977. Immune responses during human schistosomiasis mansoni. I. In vitro lymphocyte blastogenic response to heterogeneous antigenic preparations from schistosome eggs, worms and cercariae. Int. Arch. Allergy Appl. Immunol. 53:420-433.

11. Smithers, S. R., and R. J. Terry. 1965. The infection of laboratory hosts with cercariae of Schistosoma mansoni and the recovery of the adult worms. Parasitology. 55:695-700.

12. Laemmli, U. K. 1970. Cleavage of structural proteins during the assembly of the head of bacteriophage T4. Nature (Lond.). 227:680-685.

13. Towbin, H., T. Staehlin, and J. Gordon. 1979. Electrophoretic transfer of proteins from polyacrylamide gels to nitrocellulose sheets: procedure and some applications. Proc. Natl. Acad. Sci. USA. 76:4350-4354.

14. Lanar, D. E., E. J. Pearce, S. L. James, and A. Sher. 1986.
Identification of paramyosin as schistosome antigen recognized by intradermally vaccinated mice. Science (Wash. DC). 234:593-596.

15. Harris, E. H., and H. F. Epstein. 1977. Myosin and paramyosin of Caenorhabditis elegans: biochemical and structural properties of wild-type and mutant proteins. Cell. 10:709-719.

16. Waterston, R. H., H. F. Epstein, and S. Brenner. 1974. Paramyosin of Caenorhabditis elegans. J. Mol. Biol. 90:285-290.

17. Minard, P., D. P. Dean, R. H. Jacobson, W. E. Vannier, and K. D. Murrell. 1978. Immunization of mice with cobalt-60 irradiated Schistosoma mansoni cercariae. Am. J. Trop. Med. Hyg. 27:76-86.

18. Smith, M. A., and J. A. Clegg. 1985. Vaccination against Schistosoma mansoni with purified surface antigens. Science (Wash. DC). 277:535-538.

19. King, C. H., R. R. Lett, J. Nanduri, S. E. Ibiary, P. A. Peters, G. R. Olds, and A. A. F. Mahmoud. 1987. Isolation and characterization of a protective antigen for adjuvant free immunization against Schistosoma mansoni. J. Immunol. 139:4218-4224.

20. Balloul, J. M., P. Sordermeyer, D. Dryer, M. Capron, J. M. Grzych, R. J. Pierce, D. Corvallo, J. P. Lecocq, and A. Capron. 1987. Molecular cloning of a protective antigen of schistosomes. Nature (Lond.). 326:149-153.

21. Lett, R. R. 1984. Induction of resistance against Schistosoma mansoni. M.Sc. thesis. University of Alberta, Edmonton, AL. 180 pp.

22. James, S. L., E. J. Pearce, and A. Sher. 1985. Induction of protective immunity against Schistosoma mansoni by a nonliving vaccine. I. Partial characterization of antigens recognized by antibodies from mice immunized with soluble schistosome extracts. J. Immunol. 134:3432-3438.

23. Sher, A., E. Pearce, S. Hieny, and S. James. 1986. Induction of protective immunity against Schistosoma mansoni by a nonliving vaccine. IV. Fractionation and antigenic properties of a soluble adult worm immunoprophylactic activity. J. Immunol. 136:3878-3883.

24. Pearce, E. J., S. L. James, J. Dalton, A. Barrall, C. Ramos, M. Strand, and A. Sher. 1986. Immunochemical characterization and purification of SM 97, a Schistosoma mansoni antigen monospecifically recognized by antibodies from mice protectively immunized with a nonliving vaccine. J. Immunol. 137:3593-3600.

25. Cohen, C. 1982. Matching molecules in the catch mechanism. Proc. Natl. Acad. Sci. USA. 79:3176-3182.

26. Matsumoto, Y., G. Perry, R. J. Levine, R. Blanton, A. Mahmoud, and M. Aikawa. 1988. Paramyosin and actin in schistosomal teguments. Nature (Lond.). 333:76-78.

27. Pearce, E., S. James, S. Hieny, D. Lanar, and A. Sher. 1988. Induction of protective immunity against Schistosoma mansoni by vaccination with schistosome paramyosin (Sm 97), a nonsurface parasite antigen. Proc. Natl. Acad. Sci. USA. 85:5678-5682. 